\title{
Effect of load carrying on required coefficient of friction
}

\author{
Jung-Suk Seo ${ }^{\mathrm{a}}$ and Sukwon Kim ${ }^{\mathrm{b}, *}$ \\ ${ }^{a}$ Department of Physical Education, College of Education, WonKwang University, Iksan-si, \\ Jeollabuk-do, Korea \\ ${ }^{\mathrm{b}}$ Department of Physical Education, College of Education, Chonbuk National University, Jeonju-si, \\ Jeollabuk-do, Korea
}

\begin{abstract}
.
BACKGROUND: A load carrying task was identified as a major factor leading to slip and fall injuries such as overexertion and bodily reaction. Holding a load in front of the body while walking would shift the whole body center-of-mass to the front, loading additional rotational torque at the foot-ground contact.

OBJECTIVES: The present study evaluated if carrying a load would increase the likelihood of slip initiation and the slip severity.

METHODS: Eleven young and 10 older adults participated in the present study. A dry surface or a slippery surface was introduced while walking. Slip distance, peak sliding heel velocity, heel contact velocity, and required coefficient of friction were measured to test the study hypotheses.

RESULTS: The results showed that significant main effects were found in slip distance, and peak sliding heel velocity and no main effect were found in heel contact velocity and required coefficient of friction.

CONCLUSION: In conclusion, younger adults were found to slip longer and faster on the slippery surface while carrying a load. On the contrary, the older adults employed a safety-centered gait adaptation while carrying, to maintain slip initiation and severity characteristics at the same level as normal walking. Furthermore, light load carriage at $10 \%$ of body weight was suggested as a safe task for the elderly.
\end{abstract}

Keywords: Load, COM, RCOF, slips, falls

\section{Introduction}

With advancing age, there is an increasing incidence of slip-induced fall injuries [1-3]. A High percentage of disabling victims from fall accidents were over the age of 55 years old [4]. The most of the slip-induced falls take place if the frictional force $(\mathrm{F} \mu)$ opposing the movement of the foot is less than the shear force (Fh) of the foot immediately after the heel contacts the floor [5]. At the time of the heel contact, a forward thrust component of the swing foot results in a forward force (Fh) and the body weight and the downward momentum of the swing foot results in a vertical force (Fv). The ratio of forward to vertical foot forces ( $\mathrm{Fh} / \mathrm{Fv}$ ) (also called "friction demand") could predict the likelihood of severe slips [5-8]. As the differences between the friction demand and available coefficient of friction of the

\footnotetext{
${ }^{*}$ Corresponding author: Sukwon Kim, 664-14 Duckjin-dong Duckjin-gu, Jeonju, Korea. Tel.: +82 63270 2860; Fax: +82 63 270 2850; E-mail: rockwall@jbnu.ac.kr.
}

0928-7329/19/\$35.00 (c) 2019 - IOS Press and the authors. All rights reserved

This article is published online with Open Access and distributed under the terms of the Creative Commons Attribution NonCommercial License (CC BY-NC 4.0). 
Table 1

Participants' information summary

\begin{tabular}{lccccccccc}
\hline Age group & \multicolumn{4}{c}{ Age } & & \multicolumn{2}{c}{ Height } & & \multicolumn{2}{c}{ Weight } \\
\cline { 2 - 4 } \cline { 8 - 9 } \cline { 8 - 10 } & Min & Mean & Max & & Mean & SD & & Mean & SD \\
\hline Old & 70 & 73.5 & 88 & & 165.50 & 7.84 & & 73.67 & 11.38 \\
Young & 19 & 23 & 27 & & 171.79 & 6.00 & & 76.92 & 10.13 \\
\hline
\end{tabular}

floor surface increased, the number of falls would increase. The increase in forward heel contact velocity may increase friction demand during a critical time of weight transfer, and may also increase the potential for a slip-induced fall if the friction between the heel and the floor is reduced due to contamination of the floor surface [5,7-9].

A load carrying task was identified as a major factor leading to slip and fall injuries such as overexertion and bodily reaction [10]. Holding a load in front of the body while walking would shift the whole body center-of-mass to the front, loading additional rotational torque at the foot-ground contact [11]. Increasing the rotational torque during the heel contact phase of the gait may increase friction demand and frequency of slip-induced falls.

In the current study, effects of load carrying tasks and its relationship to the likelihood of slip-induced falls were examined. Aging factor was also evaluated to determine its effect on the initiation process of slip and fall accidents. An explicit assumption of current study was that quantification of biomechanical parameters associated with slip and fall accidents was an important and critical first step towards identifying significant factors influencing the outcome of slips and falls among older adults, especially when carrying a load. Understanding these critical factors will help focus our attention towards developing the most relevant intervention strategies (e.g., development of risk assessment methods and job evaluations) associated with older adults' slip and fall accidents in workplaces.

Specifically, current study hypothesized that 1) Carrying a load would increase the likelihood of slip initiation, which was characterized by increased heel contact velocity $(\mathrm{HCV})$ and required coefficient of friction (RCOF); 2) Carrying a load would also increase the slip severity, which was indicated by increased slip distance (SD) and peak sliding heel velocity (PSHV). Additionally, age-related differences would be reflected by different degrees of responses to the slipper surface.

\section{Method}

Eleven young and 10 old healthy adults participated in the current study. Informed Consent was approved by the Institute Review Board and was obtained from all participants before any data collection. Participants' information was summarized in Table 1.

Prior to performing the walking experiments, participants were fitted with standardized laboratory shoes in order to minimize possible variations due to footwear. Retro-reflectors were attached to the anatomically significant body positions [12]. The walking experiment involved participants to walk across a track embedded with two force platforms (F1 and F2, AMTI OR6-7-1000, AMTI, MA, USA), while wearing a fall arresting harness attached to an arresting rig for safety (Fig. 1). In order to obtain realistic unexpected slip and fall data, slippery surface (covered by oil) was hidden from the participants via a movable floor (F2). The movable floor was constructed to allow exchanges between oily floor and non-oily floor. Additionally, to reduce the visual effect of floor materials, the color and contrast for both the slippery and non-slippery floor materials were similar.

During the experiment, participants were instructed walk across the regular vinyl surface (dry surface) for 10 minutes with and without the load (an externally padded container $[46 \mathrm{~cm} \times 30 \mathrm{~cm} \times 30 \mathrm{~cm}$, 


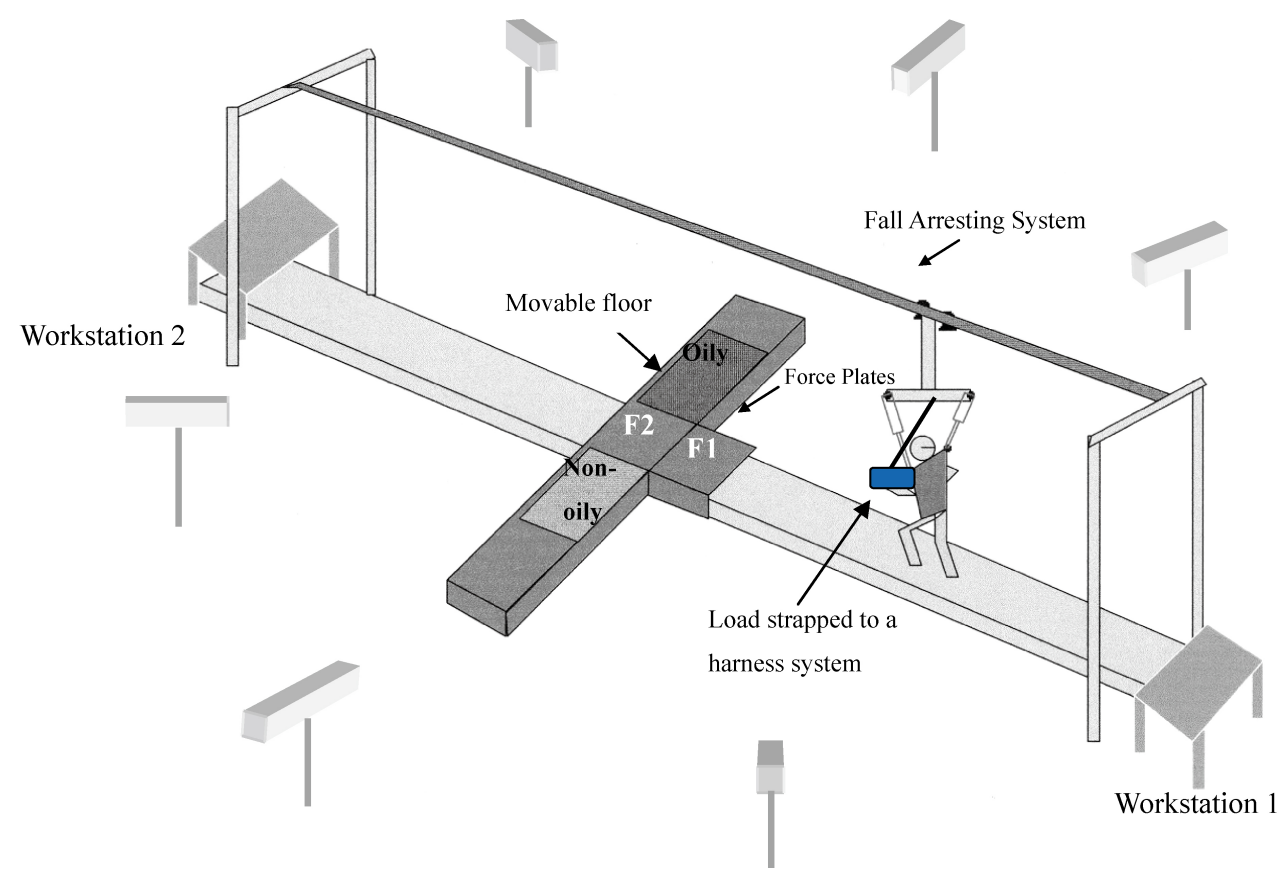

Fig. 1. Schematic diagram of the Laboratory.

$10 \mathrm{~kg}$ in weight, handles at both sides - strapped to the track for safety]). On each end, a workstation was provided to place the load for a 15 second break. Within a subsequent $10 \mathrm{~min}$ session, slippery surface was randomly introduced, and the participant's posture and ground reaction forces were recorded. The converted raw data were digitally smoothed using a fourth-order, zero-lag, low-pass Butterworth filter with a cutoff frequency of $6 \mathrm{~Hz}$ and $24 \mathrm{~Hz}$ for marker coordinate data and ground reaction forces, respectively.

Independent variables for the current study included age groups (2 levels: young and old) and floorload conditions (3 levels: dry(n), dry_w_load(nl), oil_w_load(sl)). Dependent variables include horizontal heel contact velocity, friction demand, slip distance 1 and 2, peak sliding heel velocity [9]. A computer algorithm was written in Matlab to objectively determine dependent variables. The aging effect and floor-load conditions were evaluated using two-way repeated measures analyses of variance (ANOVA). For these analyses, floor and load, where applicable, were treated as a within-subjects effect, while age was a between-subjects effect. Effects were considered significant when $p<0.05$.

\section{Results}

\subsection{SD1 (Slip Distance 1)}

Floor effect on SD1 (Table 2, Fig. 2) was found to be significant $(\mathrm{F}(2,33.4)=3.85, p=0.0312)$. Results from paired t-test indicated that only for younger group, SD1 in oil_with_load condition was significantly higher than those found in dry and dry_with_load conditions. This finding suggested that only the younger group slipped longer on the slippery surface when carrying a load, compared to the dry and dry_w_load conditions. 
Table 2

Mean and standard deviation of SD1 (mm)

\begin{tabular}{llrr}
\hline & & \multicolumn{2}{c}{ Age group } \\
\cline { 3 - 4 } & & \multicolumn{1}{c}{ Old } & \multicolumn{1}{c}{ Young } \\
\hline Floor condition & Dry (n) & $-0.24(0.36)$ & $-0.21(0.78)$ \\
& dry_with_load (nl) & $-0.45(0.67)$ & $-0.17(0.75)$ \\
& oil_with_load (sl) & $-0.15(0.89)$ & $5.52(9.05)$ \\
\hline
\end{tabular}

${ }^{*}$ Negative sign indicates backward direction.

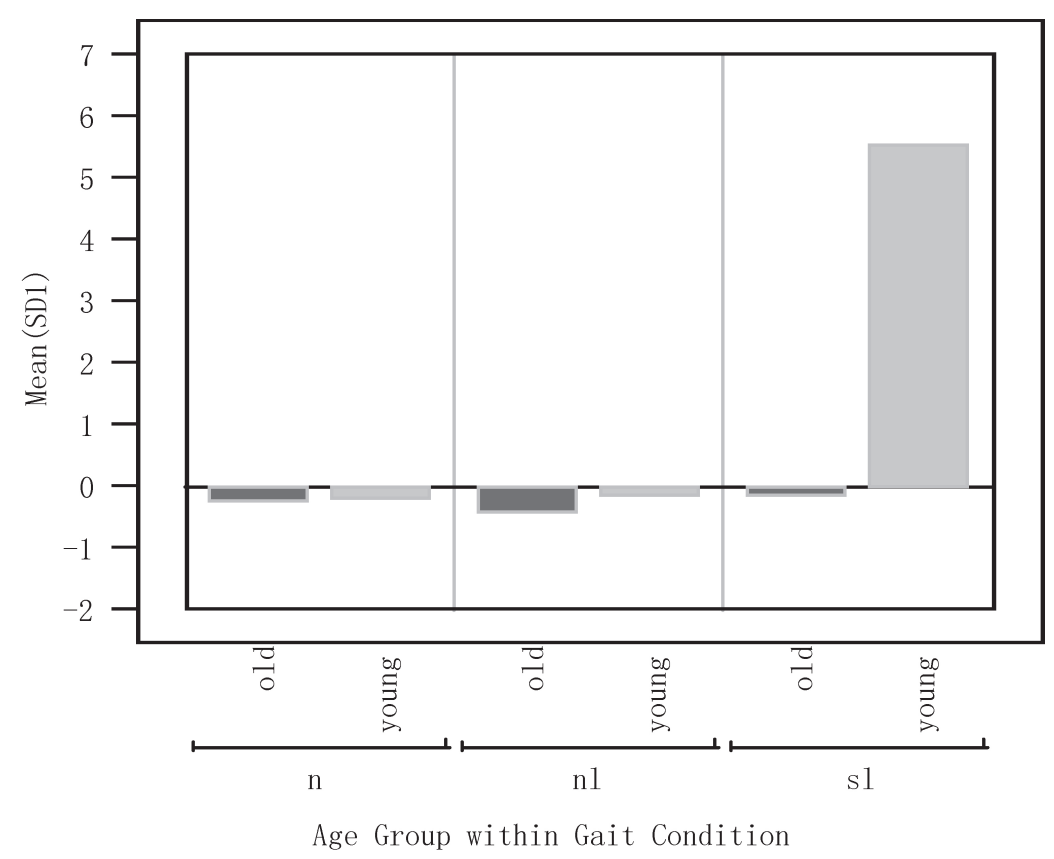

Fig. 2. Mean of SD1 (mm).

\subsection{SD2 (Slip Distance 2)}

Both floor effect $(\mathrm{F}(2,33.5)=4.9, p=0.0136)$ and aging effect $(\mathrm{F}(1,18)=5.88, p=0.0261)$ on SD2 was found to be significant (Table 3, Fig. 3). Post-hoc test indicated that only for the younger group, SD2 in oil_with_load condition was significantly higher than those observed in dry and dry_with_load conditions. This finding, similar to SD1, suggested that only the younger group slipped longer on the oil surface when carrying a load. Post-hoc test also showed a significant aging effect on SD2 only in oil_with_load condition. Younger people were found slipped longer than their older counterpart only on the oil surface when carrying a load, compared to dry and dry_w_load conditions.

\subsection{PSHV (Peak Sliding Heel Velocity)}

PSHV (Table 4, Fig. 4) was found to be significantly affected by both floor condition $(\mathrm{F}(2,33.4)=$ $5.15, p=0.0112)$ and age group $(\mathrm{F}(1,18)=6.11, p=0.0237)$. Post-hoc test indicated that only for the younger group, PHSV in oil_with_load condition was significantly higher than those observed in dry and dry_with_load conditions. This finding, from the velocity perspective, suggested that only the younger 
Table 3

Mean (SD) of SD2 (mm)

\begin{tabular}{lllc}
\hline & & \multicolumn{2}{c}{ Age group } \\
\cline { 3 - 4 } & & Old & Young \\
\hline Floor condition & Dry (n) & $1.55(0.39)$ & $2.1(0.48)$ \\
& dry_with_load (nl) & $1.45(0.87)$ & $2.26(0.73)$ \\
& oil_with_load (sl) & $1.55(1.02)$ & $37.46(48.63)$ \\
\hline
\end{tabular}

Table 4

Mean (SD) of PSHV $(\mathrm{mm} / \mathrm{s})$

\begin{tabular}{llll}
\hline & & \multicolumn{2}{c}{ Age group } \\
\cline { 3 - 4 } & & \multicolumn{1}{c}{ Old } & \multicolumn{1}{c}{ Young } \\
\hline Floor condition & Dry (n) & $48.67(11.61)$ & $66.59(12.17)$ \\
& dry_with_load (nl) & $40.12(12.22)$ & $68.49(15.6)$ \\
& oil_with_load (sl) & $64.95(32.78)$ & $643.67(786.64)$ \\
\hline
\end{tabular}

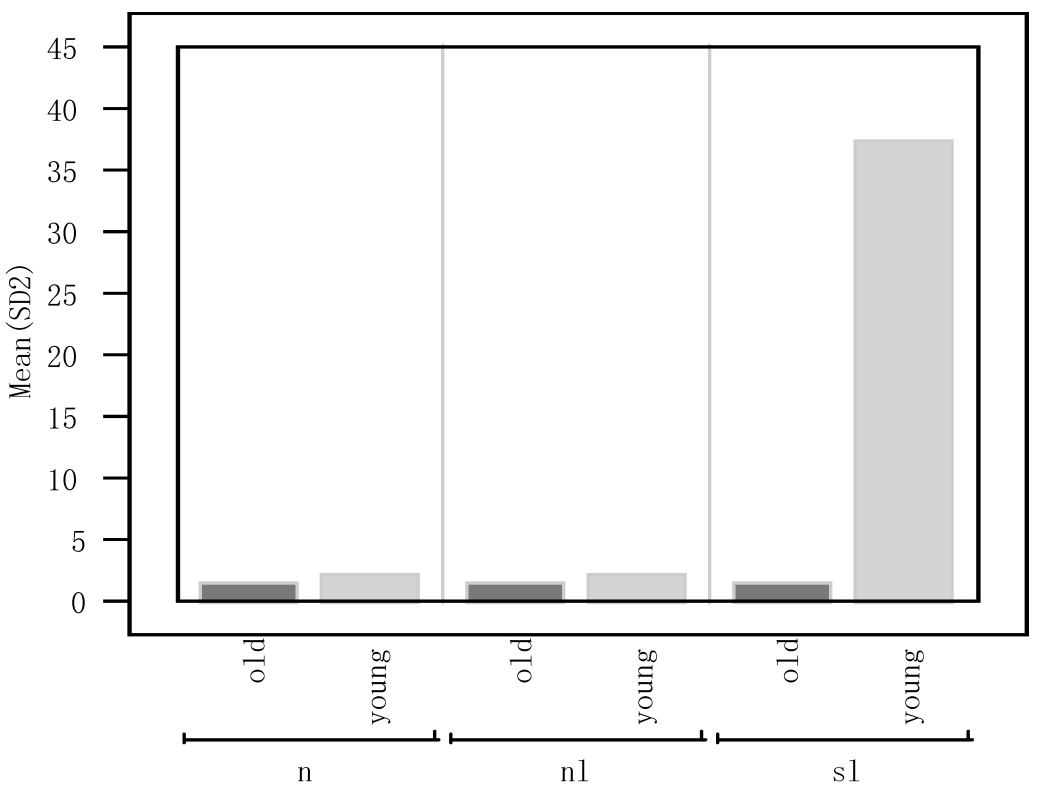

Age Group within Gait Condition

Fig. 3. Mean of SD2 (mm).

group slipped faster on the oil surface when carrying a load, compared to the dry and dry_w_load conditions. Post-hoc test also showed a significant aging effect on PHSV only in oil_with_load condition. Younger people were found slipped faster than their older counterpart only on the oil surface when carrying a load.

\subsection{HCV (Heel Contact Velocity) and RCOF (Required Coefficient of Friction)}

No difference in either HCV or RCOF was supported by the current study (Tables 5 and 6). This finding suggested that the friction demand by both younger and older group was similar across all the floor conditions. Additionally, obvious slips (10 cm or longer) were observed in 5 out of 11 younger 
Table 5

Mean (SD) of RCOF

\begin{tabular}{llll}
\hline & & \multicolumn{2}{c}{ Age group } \\
\cline { 3 - 4 } & & Old & Young \\
\hline Floor condition & Dry (n) & $-0.14(0.03)$ & $-0.15(0.04)$ \\
& dry_with_load (nl) & $-0.15(0.03)$ & $-0.14(0.04)$ \\
& oil_with_load (sl) & $-0.13(0.04)$ & $-0.15(0.05)$ \\
\hline
\end{tabular}

Table 6

Mean (SD) of $\mathrm{HCV}(\mathrm{mm} / \mathrm{s})$

\begin{tabular}{llcc}
\hline & & \multicolumn{2}{c}{ Age group } \\
\cline { 3 - 4 } & & Old & Young \\
\hline Floor condition & Dry (n) & $894.52(175.97)$ & $762.46(207.65)$ \\
& dry_with_load (nl) & $750.42(444.03)$ & $857.31(328.06)$ \\
& oil_with_load (sl) & $664.02(445.96)$ & $941.73(476.93)$ \\
\hline
\end{tabular}

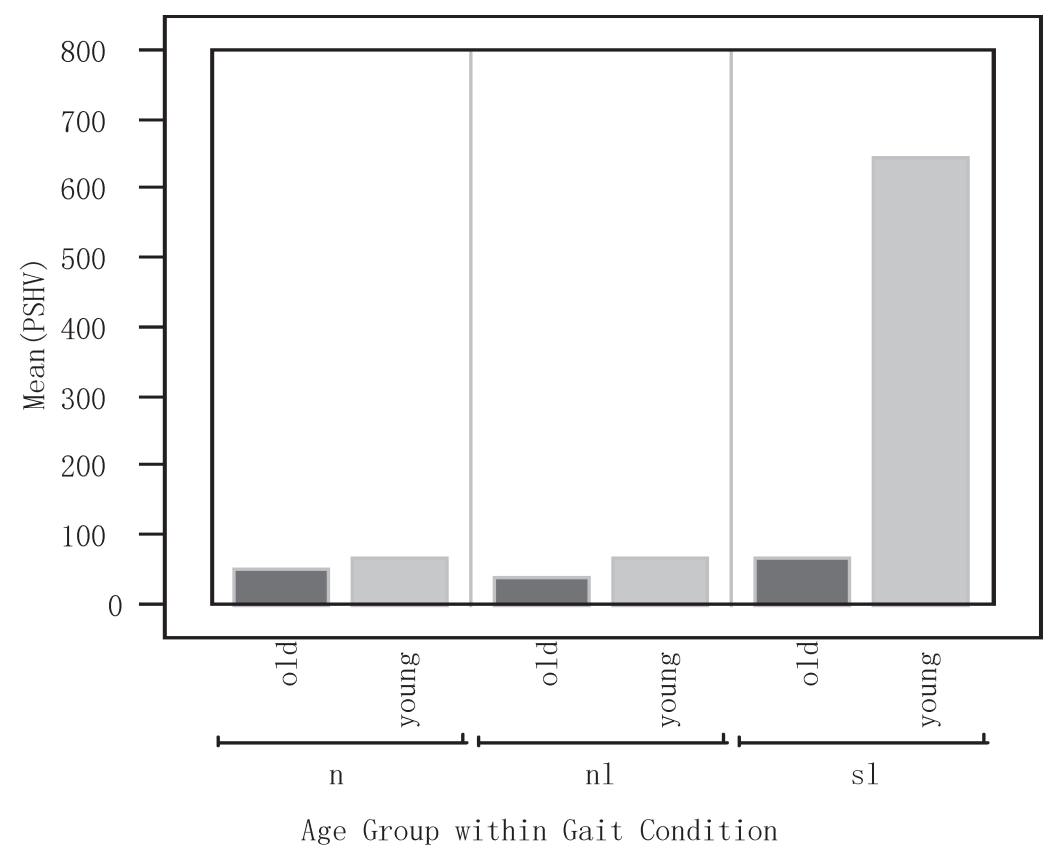

Fig. 4. Mean of PSHV (mm/s).

participants, walking on the oil surface when carrying a load. In the contrary, no obvious slip event was found in all the older participants.

\section{Discussions}

The objective of current study was to investigate the load carrying effect on kinematic gait parameter associated with slip and fall. Specifically, variables representing slip initiation (HCV and RCOF) and slip severity (SD and PSHV) were tested between different age groups and among different floor conditions.

Younger individuals were found to be highly affected by slippery surface while carrying a load. 
Significant higher SD and PSHV was found in slip-with-load condition only for the younger group. This finding indicated that younger individuals tended to slip longer and faster, which exposed them to higher risks of slip-induced fall accidents. Meanwhile, no SD and PSHV difference were found between normal-dry and dry-with-load conditions. Similar findings associated other gait parameters were also observed by previous researchers. The load carrying effect were significantly present on stride length on the slippery surface [13], but not on dry surfaces [14]. A study investigated different load level effect on heel velocity (HV) and found no load carrying effect across all the load levels for the dry surfaces [15].

Though slip severity was high for the younger group on the slippery surface, slip initiation characteristics for the younger group remain unaffected by different floor conditions. No significant floor condition effect on RCOF and HCV was found for the younger group. This finding suggested that load carrying would not change the initiation phase of slip and fall accidents. Further, load carriage (10\% of body weight in the current study) was proposed to benefit younger group on slippery surface from the slip initiation perspective.

To accommodate the total weight increase induced by load carriage, the elderly adapted their gait pattern to favor safety priority. Results from the current study showed that there was no significant floor condition effect on all the parameters in the current study. Meanwhile, the SD and PSHV were found to be significantly lower for the elderly than their younger counterparts on the slippery surface while carrying a load. This suggested the elderly actively adjusted their gait pattern to maintain the likelihood of slip initiation and severity at the same level of normal walking. Such adjustment by the elderly may be due to the fear of falling $[16,17]$.

Light load carriage level would not expose the elderly to higher risks of slip and fall accidents. All the participants in the current study were instructed to front carry $10 \%$ of their body weight. Such weight level can be considered as a light load, considering that $40 \%$ of body weight was recommended as the maximum carry weight [18]. The study investigated load level effect for the younger group and found only load level at $40 \%$ of body weight was found to have a significant effect on the stride length [15]. Together with findings associated with the elderly in the current study, it can be concluded that light load carrying was still a safe task for the elderly.

There were several limitations existing in the current study. First, to ensure the natural gait characteristic, walking velocity was not controlled for the participants. By controlling the identical walking speed or comparing floor condition related speed alterations, a future study would be able to find out the details about safety-centered gait adaptation by the elderly, and to evaluate such adaptation in terms of longterm benefit for the elderly. Second, means of load carrying in the current study was fixed to front carry $10 \%$ of body weight against the participants' body. Further research investigating different load carrying approaches and weight levels would possibly provide a recommendation on most appropriate carrying method and maximum weight level, from the consideration of minimizing slip-induced fall accidents.

\section{Conclusions}

In conclusion, younger adults were found to slip longer and faster on the slippery surface while carrying a load. On the contrary, the older adults employed a safety-centered gait adaptation while carrying, to maintain slip initiation and severity characteristics at the same level as normal walking. Furthermore, light load carriage at $10 \%$ of body weight was suggested as a safe task for the elderly.

\section{Conflict of interest}

None to report. 


\section{References}

[1] Courtney TK, Sorock GS, Manning DP, Collins JW, Holbein-Jenny MA. Occupational slips, trip, and fall-related injuries-can the contribution of slipperiness be isolated, Ergonomics. 2001; 44(13): 1118-1137.

[2] Nicklett EJ, Taylor RJ. Racial/Ethnic predictors of falls among older adults: the health and retirement study, J Aging Health. 2014; 26: 1060-75.

[3] Burns ER, Stevens JA, Lee R. The direct costs of fatal and non-fatal falls among older adults - United States, J Safety Res. 2016; 58: 99-103.

[4] Courtney TK, Webster BS. Antecedent factors and disabling occupational morbidity-insights form the new BLS data, American Industrial Hygiene Association Journal. 2001; 62: 622-632.

[5] Kim S, Lockhart TE. Effects of 8 week-balance training or weight training for the independently living elderly on the outcomes of induced slips, International Journal of Rehabilitation Research. 2010; 33(1): 49-55.

[6] Hanson JP, Redfern MS, Mazumdar M. Predicting slips and falls considering required and available friction, Ergonomics. 1999; 42(12): 1619-1633.

[7] Seo J, Kim S. Asymmetrical slip propensity: required coefficient of friction, J of Neuroengineering and Rehabilitation. 2013; 10(1): 84. DOI: 10.1186/1743-0003-10-84.

[8] Seo J, Kim S. Prevention of potential falls of elderly healthy women: gait asymmetry, Educational Gerontology. 2014; 40(2): 123-137.

[9] Lockhart T, Kim S. Relationship between hamstring activation rate and heel contact velocity: Factors influencing agerelated slip-induced falls, Gait and Posture. 2006; 24: 23-34.

[10] Bureau of Labor Statistics (BLS). USA: US. Department of Labor Website; 2000. Available from: http//www.bls.gov/ special.requests/ocwc/oshwc/cfoi/cftb135.pdf.

[11] Rohlmann A, Zander T, Graichen F, Schmidt H, Bergmann G. How does the way a weight is carried affect spinal loads, Ergonomics. 2014; 57(2): 262-270. doi: 10.1080/00140139.2014.887789.

[12] Grönqvist R, Abeysekera J, Gard G, Hsiang SM, Leamon T, Newman D, Gielo-Perczak K, Lockhart TE, Pai YC, Human-centred approaches in slipperiness measurement, Ergonomics. 2001; 44(13): 1167-1199.

[13] Leamon TB, Li KW. Load carrying and slip length. Human Factors Society. Proceedings of the $35^{\text {th }}$ Annual Meeting, San Francisco, CA. https//doi.org/10.1177/154193129103501529.

[14] Kinoshita H. Effects of different loads and carrying systems on selected biomechanical parameters describing walking gait, Ergonomics. 1985; 28: 1347-1362.

[15] Myung R, Smith JL. The effect of load carrying and floor contaminants on slip and fall parameters, Ergonomics. 1997; 40(2): 235-246.

[16] Chandler JM, Duncan PW, Sanders L, Studenski S. The fear of falling syndrome: Relationship to falls, physical performance, and activities of daily living in frail older persons, Topics in Geriatric Rehabilitation. 1996; 11: 55-63.

[17] Lawrence RH, Tennstedt SL, Kasten LE, Shih J, Howland J, Jette AM. Intensity and correlates of fear of falling and hurting oneself in the next year: Baseline findings from a Royal Center fear of falling intervention, Journal of Aging and Health. 1998; 10: 267-286.

[18] Cathcart EP, Richardson DT, Campbell W. On the maximum load to be carried by the soldier, Journal of Royal Army Medical Corps. 1923; 40: 435-443. 